\title{
PRINCÍPIOS DA PEDAGOGIA DO OPRIMIDO NA PESQUISA NOS/DOS/COM OS COTIDIANOS: NARRATIVAS DOCENTES E DIALOGIA NA IDENTIFICAÇÃO E PROMOÇÃO DE PRÁTICAS PEDAGÓGICAS EMANCIPATÓRIAS
}

\author{
OLIVEIRA, Inês Barbosa de* \\ SÁ, Luiz Carlos de**
}

\begin{abstract}
RESUMO
O objetivo deste artigo é o de estabelecer um diálogo entre o livro Pedagogia do Oprimido, de Paulo Freire, que este ano (2018) completa 50 anos de sua primeira publicação, e o trabalho com narrativas docentes em pesquisas nos/dos/com os cotidianos, entendendo que elas são capazes de contribuir para mostrar as múltiplas facetas da vida e de uso da palavra, nos permitindo fazer uma leitura ampla e atual do livro de Freire e de seu potencial emancipatório. Identificamos, nos dois casos, e por isso usamos essa noção como fundamento nuclear deste artigo, a defesa de que, contrariamente ao enunciado pela modernidade, o senso comum não é a única forma de conhecimento das populações vivendo em situação de opressão e tampouco a vida cotidiana é espaçotempo de mera repetição e inconsciência sendo, portanto, incapaz de cunhar conhecimento. Por isso entendemos que as pesquisas que fazemos nos/dos/com os cotidianos dialogam vivamente com o que Freire aponta. Trabalhando com e a partir de narrativas docentes, investimos no reconhecimento dos conhecimentos produzidos nos cotidianos das escolas, problematizados no contexto das reflexões que fazemos, coletivamente, nós e os professorxs que nos confiam suas histórias, trajetórias e questões. É assim que pudemos perceber essa circulação dialógica de saberes em ações de formação continuada. Narrativas docentes tratadas e entendidas como palavra autônoma permitem perceber a potência da dialogia como possibilidade emancipatória, tanto pelo que contribuem para o "Ser Mais" desses professorxs que conosco dialogaram quanto pelo que permitem entrever sobre o potencial emancipatório da educação dialógica.
\end{abstract}

PALAVRAS-CHAVE: Pedagogia do oprimido. Cotidiano escolar. Pesquisa com os cotidianos. Vida cotidiana. Dialogia e emancipação social.

\footnotetext{
* Professora Adjunta no Programa de Pós-graduação em Educação da Universidade Estácio de Sá e Professora Associada da Universidade do Estado do Rio de Janeiro. Doutora em Educação pela Université des Sciences Humaines de Strasbourg, Pós-doutora pelo Centro de Estudos Sociais da Universidade de Coimbra. Presidente da Associação Brasileira de Currículo e membro titular do Conselho Fiscal da ANPEd. E-mail: inesbo2108@gmail.com
}

** Professor da Universidade Estácio de Sá e rede estadual do Rio de Janeiro e doutorando do Programa de Pósgraduação em Educação da Universidade Estácio de Sá. E-mail: luizcarlosacampos@ gmail.com 


\title{
PRINCIPLES OF THE PEDAGOGY OF THE OPPRESSED IN THE RESEARCH AT SCHOOLS EVERYDAY LIFE: TEACHERS NARRATIVES AND DIALOGUE IN THE IDENTIFICATION AND PROMOTION OF EMANCIPATORY PEDAGOGICAL PRACTICES
}

\author{
OLIVEIRA, Inês Barbosa de* \\ SÁ, Luiz Carlos de $e^{* *}$
}

\begin{abstract}
The aim of this article is to establish a dialogue between Paulo Freire's Pedagogy of the Oppressed, which this year (2018) completes 50 years of its first publication, and the work with teaching narratives in everyday life researches, understanding that both are able to contribute to show the multiple facets of life and use of the words, allowing us to make a broad and current reading of Freire's book and its emancipatory potential. We have identified in both cases, and for this reason we use this notion as the nuclear basis of this article, the defense that, contrary to what is enunciated by modernity, common sense is not the only form of knowledge of the populations living in situations of oppression or everyday life is space of mere repetition and unconsciousness, and is therefore incapable of coining knowledge. That is why we understand that the research that we do in our daily lives dialogues with what Freire points out. Working with and using teaching narratives, we invest in the recognition of the knowledge produced in the daily life of schools, problematized in the context of the reflections we collectively make, and the teachers who entrust us with their stories, trajectories and questions. This is how we can perceive this dialogical circulation of knowledge in continuing teaching education actions. Narratives treated and understood as an autonomous word allow us to perceive the power of dialogue as an emancipatory possibility, both for what contribute to the "Being More" of these teachers who with us dialogued and through what they allow us to glimpse about the emancipatory potential of dialogic education.
\end{abstract}

KEYWORDS: Pedagogy of the oppressed. Everyday school life. Research with everyday life. Daily life. Dialogue and social emancipation.

\footnotetext{
${ }^{*}$ Adjunct Professor in the Postgraduate Program in Education of the Estácio de Sá University and Associate Professor of the State University of Rio de Janeiro. PhD in Education from the Université des Sciences Humaines de Strasbourg, Post-doctorate from the Center for Social Studies of the University of Coimbra. President of the Brazilian Curriculum Association and member of the Supervisory Board of ANPEd. E-mail: inesbo2108@gmail.com

** Professor at the Estácio de Sá University and Rio de Janeiro State Department and PhD student at the Postgraduate Program in Education of the Estácio de Sá University.E-mail: luizcarlosacampos@gmail.com 


\section{INTRODUÇÃO}

O objetivo deste artigo é o de estabelecer um diálogo entre o livro Pedagogia do Oprimido, de Paulo Freire, que este ano (2018) completa 50 anos de sua primeira publicação, e o trabalho com narrativas docentes em pesquisas nos/dos/com os cotidianos (OLIVEIRA, 2012), entendendo que ambas são capazes de contribuir para mostrar as múltiplas facetas da vida e de uso da palavra, nos permitindo fazer uma leitura ampla e atual do livro de Freire e de seu potencial emancipatório, política e epistemologicamente. A partir da noção do autor de que não se pode separar a leitura da palavra, ou do texto, da leitura de mundo, ou seja, da vida cotidiana, vamos considerar que para Freire não havia separação, mas afinidade entre ensinar e aprender, processo mútuo e dialógico em que "quem ensina aprende ao ensinar e quem aprende ensina ao aprender" (FREIRE, 2017a, p.25).

Abordaremos o tema do senso comum e de sua influência sobre os saberes cotidianos dos oprimidos, como questionado por Freire em sua obra e pelos estudos do cotidiano. Identificamos, em ambos os casos, a defesa de que, contrariamente ao enunciado pela modernidade, o senso comum não é a única forma de conhecimento das populações vivendo em situação de opressão e tampouco a vida cotidiana, na qual este senso comum prevalece, é espaçotempo de mera repetição e inconsciência desprovida da possibilidade de produzir conhecimento. Freire (2017) vai mesmo considerar que o discurso que o distingue essencialmente dos chamados conhecimentos científicos é uma falácia, que atua em prol da reprodução social e da legitimação do chamado poder do saber, do elitismo, e do autoritarismo que deles pode derivar.

Em sua Pedagogia da Esperança (FREIRE, 1992), na qual revisita a Pedagogia do Oprimido, Freire defende a noção de que o saber de experiência feito precisa ser respeitado como modo legítimo de conhecer e de estar no mundo dos oprimidos e que a luta pela sua superação precisa partir dele, respeitando-o e aos processos de constituição daquilo que considera uma forma de sabedoria, baseada em uma lógica própria e em uma inserção social e cultural específica. Na continuidade da argumentação, faz referência explícita à relevância desses modos de compreensão do mundo, do saber popular, com os quais os educandos chegam à escola, para uma escolarização que, sendo dialógica, permita sua superação, não numa perspectiva de substituição, mas numa tessitura que, dialogicamente, articularia uns conhecimentos aos outros produzindo novos modos de compreender e atuar no mundo, 
permitindo aos oprimidos "saber melhor o que já sabem" e participando "da produção do saber ainda não existente" (FREIRE, 1992, p. 111).

De sua parte, os estudos do cotidiano vão demonstrar que o discurso de que o senso comum - que na concepção cientificista é desqualificado por ser considerado prosaico, ambíguo e desprovido de veracidade - é a única forma de conhecimento presente na vida cotidiana é, ele também, falacioso. Esses estudos vêm demonstrando, com base no pensamento de Michel de Certeau (1994) e outros autores e nas pesquisas que vimos realizando, que a vida cotidiana é espaçotempo rico de invenções, transgressões e, com isso, de produção de conhecimentos.

Assim sendo, apresentaremos interseções entre as pesquisas nos/dos/com e a obra freireana, com destaque para a Pedagogia do Oprimido, que evidenciam haver, em ambas, o mesmo reconhecimento da produção de conhecimentos potencialmente libertadores/emancipadores nos espaçostempos da vida cotidiana que muitas vezes colaboram, de forma decisiva, para a tessitura de práticas sociais mais democráticas, mais justas e solidárias e, com isso, para a emancipação social. Apontaremos, ainda, algumas das relevantes redes trançadas entre a Pedagogia do Oprimido e as pesquisas nos/dos/com os cotidianos, na compreensão desses processos de criação de conhecimentos. Isso, apesar da força do pensamento hegemônico, que opera se mantendo indiferente a, desqualificando e rejeitando essa forma de pesquisar e a produção de tais conhecimentos, manifestando-se de forma opressora, conforme aprendemos com o livro de Freire.

A discussão será proposta como uma interlocução entre Freire e algumas pesquisas nos/dos/com os cotidianos recém-concluídas, entendendo-as como um campo que vem ganhando cada vez mais ambiência nas pesquisas de educação, embora continuem sendo mal compreendidas e interpretadas por um poder, ainda hegemônico academicamente, que insiste em afirmar que o que fazemos e escrevemos não existe ou não tem valor. Partimos, para tal, da compreensão de que a vida cotidiana

[...] não é uma parcela isolável do social. Com efeito, o quotidiano não pode ser caçado a laço quando cavalga diante de nós na exacta medida em que o quotidiano é o laço que nos permite "levantar caça" no real social, dando nós de inteligibilidade do social (PAIS, 2003, p. 31).

E, a partir daí, vamos estabelecer uma interlocução com a questão da palavra autônoma e do diálogo na obra de Freire. Nessa interação, traremos à tona a ideia de que a obra de Paulo Freire foi desenvolvida e se dirige a um grupo de pessoas e instituições que são sensíveis às 
mudanças; uma vez que, à proporção que essa pedagogia se concretiza enquanto ação cultural em favor da humanização, ela se constitui em ação reflexiva, que habilita os grupos sociais e a sociedade a promoverem o diálogo, pois o ponto que compõe o pensamento educacional do educador incide, essencialmente, na esperança de transformar o mundo, libertando-o e aos homens (a humanidade) das subordinações sociais, políticas, econômicas, e acrescentamos nós, epistemológicas.

\section{PAULO FREIRE: A CRENÇA NOS HOMENS}

Queria que vocês recebessem estes manuscritos de um livro que pode não prestar, mas que encarna a profunda crença que tenho nos homens (Trecho da carta escrita por Paulo Freire em 1968 a Jacques e Maria Edy Chonchol).

A epígrafe acima consta no fac-símile dos manuscritos do livro Pedagogia do Oprimido, cuja história principia em 1968, há exatos 50 anos. Obra que, com certeza, contém algumas das teses fundamentais do autor e também as suas percepções originais que nunca esqueceram da sua origem na "Estrada do Encanamento, 724", iniciada no dia 19 de setembro de 1921.

Essa epígrafe não reproduz a importância do seu pensamento que, enquanto ser humano, no papel de educador, sabia que precisava buscar sempre a coerência entre palavra e ação, assumindo, portanto, um comportamento cada vez mais ético, atitude que o sujeito em movimento de humanização e de libertação precisa adotar ante as outras pessoas e a sociedade, fazendo sua prática se encontrar com seu comprometimento com a ontologia do homem, destinado a "Ser Mais". Freire entendia que a mudança dos homens, e, portanto, a sua própria, deveria ocorrer de dentro para fora com o objetivo de alcançar a tolerância, a coerência e o respeito (FREIRE, 2017). Esse processo se inicia no seu primeiro trabalho como educador, no Serviço Social da Indústria (SESI), após abandonar a advocacia, e no qual logo irá ocupar o cargo de diretor da Divisão de Educação e Cultura. Foi então que Paulo Freire percebeu que o trabalho a ser desenvolvido não deveria ser assistencialista ou populista, mas popular e totalmente voltado para as camadas populares. Essa forma de trabalho dará origem ao pensamento pedagógico de Freire, porquanto é nesse convívio com o povo que ele irá ouvir e considerar aquilo que será fator essencial na composição da sua teorização, uma vez que para o educador, sua metodologia era um método de aprender e ensinar: "É que não existe ensinar sem aprender e com isto eu quero dizer mais do que diria se dissesse que o ato de ensinar exige 
a existência de quem ensina e de quem aprende" (FREIRE, 1997, p. 19). Como podemos notar no prefácio A dizer a sua palavra, de Ernani Maria Fiori:

O método Paulo Freire não ensina a repetir palavras, não se restringe a desenvolver a capacidade de pensá-las segundo as exigências lógicas do discurso abstrato; simplesmente coloca o alfabetizando em condições de poder re-existenciar criticamente as palavras de seu modo, para, na oportunidade devida, saber e dizer a sua palavra (FREIRE, 2017, p. 17).

O respeito ao educando e a conquista da autonomia são elementos fundamentais da sua teoria, que tinha como princípio basilar a dialogicidade, já que, para Freire, escutar é ir além do simples ouvir; é sensibilizar-se, é refletir, é trazer para o coração, e "o diálogo é este encontro dos homens, mediatizados pelo mundo, para pronunciá-lo, não (se) esgotando, portanto, na relação eu-tu" (FREIRE, 2017, p. 109), pois o homem se constrói na palavra que gera, na açãoreflexiva, no trabalho e não no silêncio.

Para o autor, a interpretação, quando incitada pelo diálogo, estimula a decodificação e compreensão do mundo, ou seja, a conscientização, que vai muito mais além do saber ler e escrever. Isso porque Freire considera que é a partir da própria leitura de mundo, leitura que constrói em seu cotidiano, que os indivíduos expressam o mundo e, mais importante ainda, interferem nele, participando das tomadas de decisão em qualquer esfera, buscando satisfazer suas necessidades e exercer seus direitos basilares inalienáveis, independentemente de sua posição na sociedade, já que são decorrentes da própria natureza humana. O diálogo, para Freire, é um feito humano que é constituído da palavra, que traz em si a ação e a reflexão que, juntas, transformam o mundo. "Se é dizendo a palavra com que, pronunciando o mundo, os homens o transformam, o diálogo se impõe como caminho pelo qual os homens ganham significação enquanto homens" (FREIRE, 2017, p. 109). Dessa forma, qualquer palavra imposta a qualquer indivíduo provoca a cessação do diálogo e o consequente impedimento dele atuar genuinamente no mundo, porquanto a possibilidade da sua ausência deve ser vista como dominação e opressão que impossibilitará uma práxis - reflexão a respeito do mundo que irá se converter em ação sobre o mundo - que a palavra possibilita.

Freire aponta também que o diálogo não é uma contenda belicosa ou um certame entre pessoas que estão preocupadas apenas em impor a sua verdade, ao contrário, o diálogo visa ao entendimento, à interação democrática e liberta de dominação. Essa perspectiva freireana significa conceber a interação entre sujeitos sociais como destinada, democraticamente, ao entendimento, como Habermas (1992) também defende, ao mesmo tempo em que concebe o 
diálogo como negociação de ideias, em que o que se busca é a compreensão dos diferentes pontos de vista e de suas contribuições à reflexão e à ação sociais, bem como a possível complementariedade entre eles na solução dos problemas que a sociedade se coloca, como preconiza Boaventura de Sousa Santos (1995). Nesse sentido, o papel dos processos educativos seria o de formar sujeitos para o diálogo, e nunca para a aceitação acrítica de verdades inquestionáveis. Daí a afirmação de Freire de que a educação não é neutra, pois ela pode tanto formar sujeitos dominados como sujeitos livres. Como ele mesmo nos diz: "toda neutralidade afirmada, é uma opção escondida" (FREIRE apud TORRES, 1979, p. 57). Nesse sentido, a educação pode ser uma ação cultural usada no intuito de dominar ou de libertar; dialógica ou bancária.

\section{A QUESTÃo dos COTIDIANOS E A PEDAGOGIA DO OPRIMIDO}

Freire aponta, em sua "Pedagogia do Oprimido", que é pela palavra que o homem revela sua humanidade, e que será no diálogo que o reconhecimento irá ocorrer. O diálogo, apontado na obra, é um diálogo que se faz pela pergunta reflexiva, busca desvelar a verdade que está na relação subjetividade-objetividade, não despreza a história humana, não despreza os nossos sonhos e permite a "arqueologia do contexto contido no texto" (FREIRE, 2015, p. 295). Logo, o diálogo é uma exigência existencial:

\footnotetext{
Por isto o diálogo é uma exigência existencial. E, se ele é o encontro em que se solidarizam o refletir e o agir de seus sujeitos endereçados ao mundo a ser transformado e humanizado, não pode reduzir-se a um ato de depositar ideias de um sujeito no outro, tampouco tornar se simples troca de ideias a serem consumidas pelos permutantes (FREIRE, 2017, p. 109).
}

Paulo Freire também demonstrava, ao longo de sua vida como educador, o desejo de estar no mundo com as pessoas, intervindo no mundo e motivando-as, pelo diálogo, a interferir no mundo, porque, para ele, "o diálogo não impõe, não maneja, não domestica, não sloganiza" (FREIRE, 2017, p. 228). Podemos entender que esse diálogo apontado e proposto por Freire nos permite estabelecer vínculos com as pesquisas nos/dos/com os cotidianos. Para Freire, articular a palavra verdadeira é biografar-se, ou seja, tornar-se sujeito da história, escapando da condição tão-somente de objeto da/na sociedade. Essa ideia do protagonismo dos sujeitos na construção do mundo e da sociedade está presente nas pesquisas com os cotidianos (OLIVEIRA, 2003), bem como a da importância formadora das narrativas de si (SOUZA, 2006; 
REIS, 2013), entendidas não só como um ato de biografar-se, mas também de constituir-se no mundo e com o mundo. Essas pesquisas recuperam esse protagonismo dos sujeitos quando se opõem ao pensamento hegemônico na modernidade e consideram os cotidianos como espaçostempos plenos de criações e enredamentos produtores de conhecimentossignificações e valores (ALVES, 2017) presentes tanto na constituição identitária, individual e coletiva, dos sujeitos quanto na tessitura de seus modos de estar no mundo, compreendê-lo e nele intervir (OLIVEIRA, 2003). Nesse sentido, o diálogo argumentativo formador, como o concebe Freire, é, nas pesquisas nos/dos/com os cotidianos, um elemento que reconhece e potencializa esses processos de auto-constituição e de tessitura de redes de conhecimentos, favorecendo, portanto, o desenvolvimento do protagonismo daqueles que assumem a responsabilidade de pensar e intervir na sociedade, como sujeitos históricos e de história que são.

Os estudos do cotidiano permaneceram, durante um longo período, invisibilizados pelos estudos historiográficos e epistemológicos, cuja validade inquestionável parecia anular a necessidade de se pesquisar a vida de todo dia das pessoas comuns, entendida como espaçotempo de repetição e de mesmice. Esse processo manteve abandonada uma área de estudo que se dedica a perceber e compreender os processos concretos de realização das experiências do homem. Essa concretização se desenvolve por meio das maneiras como usamos as regras e produtos que nos são dados para consumo (CERTEAU, 1994), incluindo as palavras, o que evidencia o protagonismo dos sujeitos na criação do mundo social do qual falávamos anteriormente. De sua parte, a preocupação das ciências sociais em relação aos estudos do cotidiano se funda na percepção de que essa valorização de um espaçotempo considerado menor e desimportante põe em risco a exigência de uma reflexão mais aprofundada. No entanto, entendemos que é precisamente pelo acesso que buscam àquilo que, concretamente, constitui o mundo social e suas instituições, que os estudos do cotidiano nos permitem apreender determinadas demandas sociais negligenciadas pelo pensamento hegemônico da modernidade, que o enxerga meramente como espaço de aplicação e repetição de regras, teorias ou estruturas da sociedade.

O paradigma moderno pode ter seu início identificado no momento em que Galileu e Newton confirmaram a validade de seus experimentos, matematizando-os, quantificando-os e, no caso do segundo, sobretudo, formulando leis "universalmente válidas" a partir desses resultados. O processo que se seguiu, de produção da exclusividade deste modo de validação de conhecimentos como única racionalidade possível e aceitável, acabou por dar origem ao que 
hoje chamamos de cientificismo, uma forma de dogmatização dessa ciência e de seus métodos que vem invalidando todas as demais formas de compreender o mundo, inclusive aquelas produzidas nos diversos cotidianos sociais, relegados à condição de espaçotempo do senso comum, da repetição e da ausência de reflexão. No entanto, as dificuldades desta racionalidade em se adequar aos estudos dos fenômenos sociais, nos quais muitos elementos não controláveis e não quantificáveis se fazem presentes, levam à suspeição de sua ineficiência para esse tipo de pesquisa, além de o avanço das próprias ciências naturais ter demonstrado, com Einstein, que não há uma realidade física incondicional e imutável. Em uma de suas frases célebres, podemos resumir o que tratamos aqui, e do questionamento que, com Freire, fazemos do pensamento da modernidade. Einstein afirma que: "nem tudo o que conta pode ser contado, e nem tudo o que pode ser contado conta" (EINSTEIN apud OLIVEIRA, 2010), ao mesmo tempo em que lança dúvidas sobre o cosmos e sobre o que somos nele e em sua infinitude. Na Pedagogia do Oprimido, Freire aponta para esse debate logo na abertura do livro, em clara alusão aos problemas que o mundo vivenciava na época e à busca de outros modos de conhecer e intervir neste mesmo mundo:

Mais uma vez os homens, desafiados pela dramaticidade da hora atual, se propõem a si mesmos como problemas. Descobrem que pouco sabem de si, de seu "posto no cosmos", e se inquietam por saber mais. Estará, aliás, no reconhecimento do seu pouco saber sobre si uma das razões desta procura (por saber mais). Ao se instalarem na quase, senão trágica, descoberta do seu pouco saber de si. Se fazem problema a eles mesmos. Indagam. Respondem, e suas respostas os levam a novas perguntas (FREIRE, 2017, p. 39).

Saber mais pesquisando, suspeitando do já sabido e buscando caminhos e alternativas para a compreensão do mundo físico e social, e na gestação de modos de intervenção nele e sobre ele. Assim, embora ainda atualmente alguns pesquisadorxs vejam o cotidiano como uma repetição do senso comum, enxergando somente o aspecto quantitativo da realidade, de fato, esse espaçotempo vai muito além de uma simples repetição rotineira do que se faz, já que não procedemos da mesma maneira quando fazemos. O modo "como" executamos, mesmo as chamadas tarefas repetitivas do dia a dia, se modifica sempre e permanentemente.

Os estudos do cotidiano vêm procurando, justamente, recuperar a importância daquilo que não integra as estatísticas e regulamentações para redefinir o próprio cotidiano, superando a ideia, ainda dominante, de que este resume-se ao espaço do senso comum e da regulação. Recuperando os aspectos singulares e qualitativos de práticas, aparentemente repetidas ad infinitum, percebemos que, na forma de fazer cada uma dessas atividades, nunca há 
repetição. Em sua infinita rebeldia, o cotidiano não se deixa dominar por normas e regulamentos formais, exatamente porque as ações cotidianas, na multiplicidade de formas de sua realização, não são e não podem ser repetidas no seu "como" (OLIVEIRA, 2003a, p. 5).

Ao contrário do que afirma o pensamento reducionista sobre o cotidiano, não há uma repetição sistemática de ações no dia a dia. Esse pensamento que só considera a dimensão quantitativa das realidades, avalia erroneamente o fato de fazermos "a mesma coisa" muitas vezes, privilegiando este "o que fazemos" e quantificando-o em detrimento do "como fazemos", mutável e de impossível quantificação. Assim sendo, desse ponto de vista, do modo como a vida acontece concretamente, não há repetição no cotidiano. Ele é o espaçotempo no qual nos construímos e às nossas identidades, crenças e modos de compreender o mundo, de pronunciálo, como bem afirma Freire, e de, a partir daí, enfrentar situações de opressão, de exclusão, de não reconhecimento.

Pronunciar-se sobre o cotidiano é referir-se às relações edificadas nas tessituras do dia a dia e que se concretizam como identidade dos diferentes grupos sociais. Possibilita refletir a respeito das percepções trazidas à tona por essas rotinas, que são geradoras de novos enfoques e de produção de conhecimentos, de efetivação de experiências promotoras de mais igualdade social, de reconhecimento do outro e de suas enunciações. Assumindo a perspectiva de Edgar Morin quando define o pensamento complexo, vamos compreender que é no espaçotempo do cotidiano que o entrelaçamento ao qual ele se refere ocorre, que este é, portanto, por definição, o espaçotempo do complexus:

[...] é o que está junto; é o tecido formado por diferentes fios que se transformam numa só coisa. Isto é, tudo isso se entrecruza, tudo se entrelaça para formar a unidade do complexus; porém, a unidade do complexus não destrói a variedade e a diversidade das complexidades que o teceram (MORIN, 1998, p. 188).

Assim, ao pronunciarmos o mundo por meio de uma narrativa, essa narrativa não é um retorno ao descritivo que abalizou a historicidade clássica. Nela, está presente o fato de sermos narradores que traçam e trançam texturas a partir das variedades das narrativas que nos chegam ou chegaram, e nas quais iremos fixar os fios do nosso modo de contar. Importante lembrar que aqui nos referimos a quaisquer narrativas, considerando com Freire que "dizer a palavra verdadeira, que é práxis, é transformar o mundo, dizer a palavra não é privilégio de alguns homens, mas direito de todos os homens" (FREIRE, 2017, p. 109). É a partir dessa ideia que vamos pensar o oprimido, pelo viés estabelecido no livro de Freire, como sendo aquele ser 
humano que é impedido da sua condição de "ser mais", uma vez que lhe é tirado o direito de dizer o seu mundo como sujeito, o que inviabiliza o diálogo. O autor aponta que: "Não há também diálogo se não há uma intensa fé nos homens. Fé no seu poder de fazer e refazer. De criar e recriar. Fé na vocação de ser mais, que não é privilégio de alguns eleitos, mas direito dos homens" (FREIRE, 2017, p. 110). Não haverá diálogo se, enquanto ouvintes, nos negarmos a ouvir a enunciação do outro, fruto da experiência construída no seu cotidiano, mas que nunca reconhecemos como válida e olhamos com preconceito.

\section{NARRATIVAS DOCENTES COMO LUTA CONTRA A OPRESSÃO: DIÁLOGOS ENTRE CONHECIMENTOS NA PESQUISA EM EDUCAÇÃO}

No capítulo 2 de sua obra, Freire encerra discutindo o tema "ninguém se liberta sozinho", uma vez que essa libertação ocorre na comunhão que se dá no cotidiano. Os sujeitos que foram vistos como "seres fora de..." nunca permaneceram "fora de..."; sempre estiveram dentro da estrutura que os transformou em "seres para os outros"; eles viveram e vivem no mesmo espaçotempo, como podemos perceber nos estudos sobre os cotidianos, que sempre os percebem como "seres para si" que transformam a estrutura que os enxerga como marginalizados (Freire, 2017, p. 84-85). Como nos aponta Oliveira (2003a, p. 5), “[...] as lógicas que presidem o desenvolvimento das ações cotidianas são profundamente diferentes daquela com a qual nos acostumamos a pensar na modernidade. Nesses processos diferentes e complexos de viver e criar nos múltiplos espaços/tempos cotidianos [...]”.

O que vimos fazendo em nossas pesquisas nos/dos/com os cotidianos dialoga vivamente com o que Freire aponta e, pelo trabalho desenvolvido com e a partir de narrativas docentes, buscamos investir no reconhecimento dos conhecimentos produzidos nos cotidianos das escolas, problematizados no contexto das reflexões que fazemos, coletivamente, nós e os professorxs que nos confiam suas histórias, trajetórias, dúvidas e soluções. Somos todxs protagonistas, assumindo-nos para além do ser para os outros. Professorxs e pesquisadorxs em diálogo, aprendendo uns com os outros, os conhecimentos com que operam nos seus modos de habitar e pronunciar o mundo.

É assim que temos podido perceber essa circulação dialógica de saberes em algumas vivências - experiências compartilhadas com colegas atuando nas escolas e em universidades - de formação continuada e no nosso curso de extensão, ao qual demos o nome do mais clássico espaçotempo de diálogos democráticos, o CHOPP (Contando Histórias e Ouvindo: Papos de $======$ 
Professoras), sigla que designa o trabalho de pesquisa e extensão que fazemos em parceria com professorxs de redes municipais do Rio de Janeiro e com grupos de pesquisa que se inspiram dos mesmos referenciais teórico-metodológicos que o nosso. Entendemos que esse trabalho vem propiciando aos nossos parceiros docentes da Educação Básica possibilidades de autoenunciação, de tomada de uma palavra, a própria, que o pensamento e as práticas acadêmicas hegemônicas lhes negam. E, por isso, nos vemos trabalhando na perspectiva da dialogia freireana.

Nos últimos anos, desenvolvemos projetos de pesquisa e realizamos diferentes cursos de extensão baseados no potencial autoformador das narrativas docentes, estabelecendo com elas diálogos sobre os temas que nos orientam na busca de experiências curriculares de caráter emancipatório, a saber, a justiça cognitiva - justiça na relação entre os diferentes conhecimentos presentes nos cotidianos das escolas - e a cidadania horizontal - aquela que toca as relações horizontais entre cidadãos e a solidariedade entre eles na tessitura do bem-estar comum. Essa justiça e cidadania solidária só são possíveis em cenários nos quais a palavra proferida seja de autoria, e não de repetição ou tutela.

Outro fator que nos leva a usar as narrativas docentes, entendidas na perspectiva da dialogia freireana como ferramenta de libertação e de autorreconhecimento, é o fato de que esse tipo de atividade narrativa se constitui como experiência formativa para professorxs, na medida em que essa valorização da palavra que dizem contribui para o "ser mais" desses sujeitos, praticantespensantes (OLIVEIRA, 2012) dos cotidianos, cujos conhecimentos e o reconhecimento deles vêm sendo negados pelo primado dos conhecimentos abstratos sobre a escola. Nesse exercício cotidiano, aqueles que narram têm a possibilidade de (re)viver e repensar suas experiênciaspráticas, amadurecendo ideias e propostas com as quais trabalham e pretendem trabalhar. Assim, produzem diálogos entre o que fazem, o que desejam, o que lhes é possível fazer e o que pensam e, nesse percurso, se formam ou (auto)formam exercitando uma reflexão que vai além da naturalização das ações cotidianas, criando outros sentidos para a sua docência, sendo mais.

Dessa forma, percebemos a formação como uma rede que se emaranha na produção de conhecimentos comuns (comuns porque estão ali no cotidiano e também comuns porque se tornam parte da vida de todos) e que também se singularizam por meio da riqueza que a vida de cada um nos mostra em suas particularidades e diferentes aprendizagens, criando uma 
história acerca da produção do fazer pedagógico, cuja dialogia constitutiva emerge e é valorizada por meio dessas reflexões e práticas dialógicas.

Assim, ao mesmo tempo em que aprendemos sobre processos pedagógicos cotidianos com as narrativas, as percebemos como modos de potencializar uma formação docente centrada nos conhecimentos e reflexões dos professorxsnarradorxs a respeito de suas próprias experiênciaspráticas, estudadas coletivamente, dialogicamente, a partir das enunciações individuais. Trazemos, então, para este texto e para a reflexão que pretendemos desenvolver, a voz de Maria ${ }^{1}$, professora do quinto ano de uma escola pública federal no Rio de Janeiro.

Ando cansada de debater a questão do currículo, o que deve ser ensinado, de que forma, vejo muita conversa e pouca ação, muita teoria que, para mim, depois de quase 30 anos de magistério, não tem mais sentido discutir. Fecho a minha sala e faço com meus alunos aquilo que acredito ser bom para eles, lemos muito, escrevemos, fazemos rodízio de livros, rodas de leitura, debates, testes diferentes... Aprendemos juntos, na troca. Vejo que isto dá certo, pois estabeleço relações que acredito serem importantes, permito que meus alunos falem sobre o que estão aprendendo sempre e mais, meus alunos têm seguido para a série seguinte com os conteúdos bem trabalhados (MARIA, 2009).

Que pistas Maria está dando com essa fala? O que está nos dizendo? Podemos atribuir múltiplos sentidos ao que ela diz, mas nosso interesse aqui recai sobre a forma utilizada por ela para nos dizer da falta que a dialogia norma-prática faz. Vemos em sua fala que ela tem a preocupação de não abandonar os conteúdos quando diz "meus alunos têm seguido para a série seguinte com os conteúdos bem trabalhados", ao mesmo tempo em que questiona o que considera excessos teóricos desvinculados das experiênciaspráticas existentes e possíveis, só acessíveis por meio do diálogo verdadeiro entre autoridades e professorxs.

Maria reafirma em sua fala a importância cotidiana desse diálogo que propicia aprendizagens mútuas, e narra os modos como faz com que ele aconteça, alegando estar cansada de "muita conversa e pouca ação, muita teoria", que podemos interpretar como sendo um cansaço de imposições "bancárias” que comprometem sua autonomia no fazer e no dizer.

Em outra experiência de formação dialógica por meio de narrativas docentes e debates sobre elas, encontramos um diálogo entre conhecimentos e modos de estar no mundo, um diálogo que permitiu desembocar no reconhecimento do direito à diferença, de respeito mútuo, de solidariedade, como previsto na perspectiva libertadora de educação. 
Contou a professora, com certo orgulho do trabalho realizado, que José ${ }^{2}$ chegou à sua turma com fama de brigão, de criança que bate nas outras, mas que foi muito bem recebido pela sua turma.

As crianças foram muito receptivas e violência a gente não teve nenhum problema com o José. Mas eu não sei se foi por causa do discurso que foi tendo ao longo do ano de "cuidado com o José", "vamos tomar conta", "vamos ajudar", tudo que ele faz as crianças aplaudem, batem palmas... ${ }^{3}$

Na continuidade de sua narrativa, deixa entrever de que modo um trabalho com intenção solidária pode levar alunos, ainda crianças, a praticá-la.

\begin{abstract}
E aí na semana passada, a gente descobriu que o José tinha feito aniversário, num dia que foi de reunião pedagógica. Como todo dia de aniversário eu desenho um bolo no quadro para as crianças, a gente canta parabéns e tal, ele pediu pra desenhar um bolo pra ele, porque nunca ninguém tinha desenhado um bolo pra ele. Nós não sabíamos a data de aniversário dele, fui procurar saber e aí a gente descobriu que já tinha passado. Aí eu falei para as crianças: "Gente, o aniversário Evanildo passou e ninguém ficou sabendo." Aí eles mesmos se organizaram, sem falar pra mim, que iam fazer, sem me pedir autorização, vieram no recreio dizendo que iam fazer uma festa pro José. Aí eu falei "Eu dou o bolo e vocês preparam o restante." Trouxeram bola, enfeitaram a sala, levaram ele pra fora de sala pra enganá-lo e ele nem percebeu que ia ter festa pra ele mesmo. Quando ele entrou, ele se escondeu... Aí eu: “Assopra a vela José!” (...) Ele assoprou a vela, mas não queria dar o primeiro pedaço de bolo. Ele não sabia pra quem dar, porque ele não sabia pra quem ele tinha que dar. "Você tem que dar pra quem você mais gosta aqui da sala." Aí ele deu pra uma menina. Foi uma coisa!!! Vi um cuidado especial da turma com essa criança, que foi tão mal vista por mim no início, que fiquei tão amedrontada de pegar o José, mas eu sinto sim que as crianças, por elas mesmo cuidam um pouquinho dele apesar de ser terrível às vezes.
\end{abstract}

No diálogo que se seguiu, falamos sobre o comportamento de José, do modo como ele age infantilmente apesar de seus quatorze anos, em virtude de sua condição mental. No entanto, reconhecendo sua responsabilidade educadora, a professora entende, nos conta e se orgulha disso, que isso não é motivo para excluí-lo, para desconsiderar seus direitos, para não dialogar com as suas possibilidades. Dialoga com José, com o que ele pode ser, e leva os demais alunos a assumirem atitude semelhante, «cuidando» dele, respeitando-o. Ou seja, a presença de José emerge dessa experiência narrada como uma experiência de protagonismo da docente, e dele, e da dialogia instaurada nessa sala de aula, nessa prática da solidariedade que permite à professora fazer e dizer um trabalho sobre a necessidade de respeito à diferença, de reconhecimento dos direitos que José tem, independentemente de sua condição «especial».

Essa prática de solidariedade, de reconhecimento do outro, sobretudo por se tratar de um aluno especial, um «incluído», permite-nos desenvolver outras reflexões sobre esta questão 
tão importante, a da superação dos processos de opressão/exclusão nas escolas, em busca da dialogia e da solidariedade. O convívio sem medo, a tessitura de diálogos e do reconhecimento mútuo, pode ajudar nossa sociedade a superar preconceitos como aqueles relacionados à diversidade étnico-racial e cultural, às questões ligadas à orientação sexual, aos padrões e hábitos de consumo das diferentes populações e grupos sociais, sempre contribuindo para substituir a segregação por interação horizontalizada, dialógica.

Para a argumentação central deste texto, cabe registrar que a cooperação entre os alunos que permitiu a integração de José na classe também pode ser pensada de modo mais amplo, como um meio de levar todos e cada um à compreensão de que os bons ambientes, nos quais experimentamos convivências dialógicas, solidárias, são mais potentes na tessitura da libertação de todos, da sociedade mesma, na medida em que prescindem da competição e operam com base no reconhecimento mútuo.

\section{PEDAGOGIA DO OPRIMIDO: DIÁlOGOS NOS/DOS/COM OS COTIDIANOS COMO RUPTURA DA HIERARQUIA HEGEMÔNICA}

A Pedagogia do Oprimido é reconhecida por muitos de seus críticos como uma obra de leitura difícil, mesmo não sendo uma obra extensa. O que os críticos apontam é que a obra possui uma linguagem confusa, utiliza termos inventados e palavras às quais o autor confere um significado alegórico - chavões - sem uma definição clara do sentido que teriam. Assinalam, ainda, que muitas vezes, não existe uma conexão lógica entre uma frase e a outra, entre um conceito e o outro, e o que é mais grave ainda, entre um parágrafo e o outro. Ainda assim, a validade de sua noção central, de que existem dois tipos de educação - a opressora (a educação bancária) e a libertadora (a educação dialógica) - é hoje reconhecida por educadores e estudiosos de diferentes campos e matizes, até mesmo por aqueles que criticam a obra, que reconhecem a validade política e epistemológica da proposta freireana.

De nossa parte, entendemos o que Paulo Freire sempre apregoou sobre a leitura ser muito mais que simplesmente o procedimento de entender as palavras como a defesa da necessidade de a escola dialogar com conhecimentos dos estudantes e respeitar seus saberes pregressos ao buscar ensinar-lhes novos, tal como propõem os estudos e pesquisas com os cotidianos. É uma compreensão vinculada à nossa abrangência e à compreensão do que se lê, pois, a leitura não pode ser vista como uma forma reducionista de unir sinais gráficos. 
Inegavelmente, existem várias formas de se fazer uma leitura, no entanto, nenhuma delas deve ser feita de forma apenas decifratória.

Ler, segundo Freire, não é caminhar sobre as letras, mas interpretar o mundo e poder lançar sua palavra sobre ele, interferir no mundo pela ação. Ler é tomar consciência. A leitura é antes de tudo uma interpretação do mundo em que se vive. Mas não só ler. É também representá-lo pela linguagem escrita. Falar sobre ele, interpretá-lo, escrevê-lo. Ler e escrever, dentro desta perspectiva, é também libertar-se. Leitura e escrita como prática de liberdade (ALMEIDA, 2009, p. 26).

Freire nos traz, ainda, o debate entre a humanização e a desumanização, que nada mais é do que a coisificação dos seres humanos, e a Pedagogia do Oprimido nada mais é que uma pedagogia voltada para a humanização do indivíduo livre, desalienado e seu reconhecimento como "eu constituído", dono de sua palavra e do direito de dizê-la na expressão de seus conhecimentos e modos de compreensão do mundo. A outra estaria ligada à perpetuação do status quo, dando ênfase à permanência das desigualdades e iniquidades sociais, não favorecendo sua libertação das incongruências sociais, mantendo silenciadas as enunciações dos grupos sociais subalternizados. Como aponta Boaventura de Sousa Santos (2002, p. 78), em claro diálogo com a noção freireana da pluralidade de conhecimentos e ignorâncias no/do mundo:

Todo o conhecimento implica uma trajetória, uma progressão de um ponto ou estado A, designado ignorância, para um ponto ou estado B, designado saber. As formas de conhecimento distinguem-se pelo modo como caracterizam os dois pontos e a trajetória que conduz de um ao outro. Não há, pois, nem ignorância geral e nem saber em geral. Cada forma de conhecimento reconhece-se num tipo de saber que contrapõe um certo tipo de ignorância, a qual, por sua vez, é reconhecida como tal quando em confronto com esse tipo de saber. Todo saber é saber sobre uma ignorância e, vice-versa, toda ignorância é ignorância de um certo saber.

Os variados diálogos que se constituem nos cotidianos, como aqueles que trouxemos para este texto, descortinam a força do domínio, as relações sociais e culturais dos que exercem o poder, na tentativa silenciar o outro. Com as pesquisas nos/dos/com os cotidianos temos buscado, com sucesso, desinvisibilizar essas vozes, buscando favorecer as possibilidades de "ser mais" dos seus sujeitos. No trabalho de pesquisa com escolas e docentes, isso significa ouvir a palavra de seus sujeitos, dialogar com ela sem hierarquias, na perspectiva do reconhecimento mútuo e do diálogo. Entendemos, com Freire (2017, p. 134) que o importante é "propor aos indivíduos dimensões significativas de sua realidade, cuja análise crítica lhes possibilite reconhecer a interação entre as partes (Freire, 2017, p. 134). 


\section{CONSIDERAÇÕES FINAIS}

Buscamos, neste texto, tornar evidente algo que Freire apresenta e defende em sua Pedagogia do Oprimido sobre a constituição dos modos de compreender o mundo e de nele agir. Reafirmamos, ainda com Freire, que estas não se podem constituir no silêncio, uma vez que é no diálogo, produzido a partir do cotidiano, que ocorre a transformação da sociedade que oprime, na que será (ou poderá ser) mais igualitária, na qual o oprimido passa a desempenhar a sua predisposição “ontológica de "Ser Mais"” (FREIRE, 2017, p.71), pois somente por intermédio dele o mundo poderá ser para todos, sem distinção.

A partir desse entendimento, trouxemos resultados de nossas pesquisas, em que as narrativas docentes tratadas e entendidas como palavra autônoma permitem perceber a potência da dialogia como possibilidade emancipatória, tanto pelo que contribuem para o "Ser Mais" dessxs professorxs que conosco dialogaram quanto pelo que permitem entrever sobre o potencial da educação dialógica. Ela aparece como elemento fundante da ruptura das injustiças cognitivas cometidas pela educação bancária e sua crença na superioridade do saber formal, teórico, sobre os saberes da experiência (inclusive docente) - como explicitado pela primeira professora referida neste texto - quanto para a superação de processos discriminatórios e excludentes que vitimam tantos estudantes das nossas escolas públicas.

Entendemos que essas pesquisas e a leitura que elas permitem fazer com base nos critérios da dialogia freireana permitem entrever modos e possibilidades de diálogos promotores de conhecimentos e reconhecimentos, de relações humanas e sociais mais democráticas e, portanto, que contribuem com a emancipação social na medida em que dialogicamente constituímos relações que transcendem as atuais relações de poder, e de opressão dos que o detêm sobre outros, mas relações de autoridade partilhada, entre diferentes sujeitos e leituras de mundo.

Nesse sentido, pensamos ser possível afirmar que a desinvisibilização de práticas pedagógicas de caráter emancipatório já em andamento em muitas escolas contribui decisivamente para a recuperação da esperança em "um mundo melhor"; esperança além da espera, ativa na construção da possibilidade efetiva de sua realização. Esperança do verbo esperançar:

É preciso ter esperança, mas ter esperança do verbo esperançar; porque tem gente que tem esperança do verbo esperar. E esperança do verbo esperar não é esperança, é espera. Esperançar é se levantar, esperançar é ir atrás, esperançar é construir, esperançar é não desistir! Esperançar é levar 
adiante, esperançar é juntar-se com outros para fazer de outro modo (CORTELLA, 2001, s/n).

Assim, podemos finalizar a contribuição que este texto pretende ser para as reflexões em torno da Pedagogia do Oprimido e do potencial daquilo que ela nos ensina para pensar modos de pesquisar e trabalhar com a palavra docentediscente nos/dos cotidianos escolares reconhecendo-as (a pesquisa e a palavra) como formas de diálogo, entendido este como relação que ocorre entre as pessoas no cotidiano, e considerando o seu alargamento como uma possibilidade que continuará a produzir não só conhecimentos, mas também se constituirá como núcleo de uma educação libertadora e democrática. Isso porque percebemos na obra de Paulo Freire que o diálogo não é o meio, mas o alicerce do seu pensamento. Portanto, podemos considerar que será nessas relações cotidianas/dialógicas que o indivíduo irá atuar para transformar o mundo e ao mesmo tempo ser transformado por ele. 


\section{REFERÊNCIAS}

ALMEIDA, Fernando José de. Folha Explica Paulo Freire. São Paulo: Editora Publifolha, 2009.

ALVES, Nilda. Formação de docentes e currículos para além da resistência. ANPEd: Revista Brasileira de Educação. v. 22, n. 71, 2017.

CERTEAU, Michel. A invenção do cotidiano 1: as artes de fazer. 2.ed. Petrópolis: Vozes, 1994.

CORTELLA, Mário Sérgio. A resignação como cumplicidade. Folha de São Paulo, São Paulo. 08 nov. 2001. Disponível em: https://www1.folha.uol.com.br/fsp/equilibrio/eq0811200123.htm. Acesso em: 20 nov. 2018.

FREIRE. Ana Maria Araújo. A Leitura do mundo e a leitura da palavra em Paulo Freire. Cadernos Cedes, Campinas, v. 35, n. 96, p. 291-298, maio-ago., 2015. Disponível em: http://www.scielo.br/pdf/ccedes/v35n96/1678-7110-ccedes-35-96-00291.pdf. Acesso em: 21 ago. 2018.

FREIRE, Paulo. Pedagogia do Oprimido. São Paulo: Paz e Terra, 2017.

Terra, 2017a.

Pedagogia da Autonomia: saberes necessários à prática educativa. São Paulo: Paz e 1997.

Professora sim, tia não: cartas a quem ousa ensina. Editora Olho d’Água. São Paulo,

Pedagogia da Esperança: um reencontro com a Pedagogia do oprimido. São Paulo: Paz e Terra, 1992.

HABERMAS, Jürgen. Éthique de la discussion. Paris: Cerf, 1992.

MORIN, Edgar. Ciência com consciência. Rio de Janeiro: Bertrand Brasil, 1998.

OLIVEIRA, Inês Barbosa de. Currículos praticados: entre a regulação e a emancipação, Rio de Janeiro: DP\&A, 2003.

2003a. Currículos praticados: regulação e emancipação no cotidiano escolar. Anais da

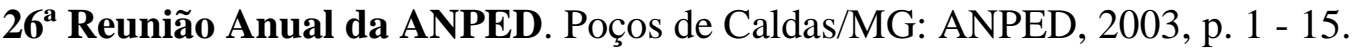

Cenas do cotidiano escolar: descobertas e invenções de pesquisas com narrativas imagéticas. Revista Teias (UERJ. Online), v.11, jan-abr, 2010, p. 1 - 13, 2010.

Currículo como criação cotidiana. Petrópolis/RJ: DP et Alii, 2012.

OLIVEIRA, Inês Barbosa de; ALVES, Nilda. (Org.). Pesquisa nos/dos/com os cotidianos das escolas. Petrópolis: DP et Alii, 2008.

REIS, Graça Regina Franco da Silva. A narrativização das práticas como prática de liberdade Instrumento: Revista de Estudos e Pesquisas em Educação. Juiz de Fora, v. 15, n. 2, jul./dez. 2013.

Disponível

em:

https://instrumento.ufjf.emnuvens.com.br/revistainstrumento/article/view/2652

TORRES, Carlos Alberto Torres (org.) Entrevista com Paulo Freire. In. Diálogo com Paulo

Freire. São Paulo: Loyola, 1979. 
SANTOS, Boaventura de Sousa. Reconhecer para libertar: os caminhos do cosmopolitismo multicultural. Introdução: para ampliar o cânone do reconhecimento, da diferença e da igualdade. Rio de Janeiro: Civilização Brasileira, 2003.

A crítica da razão indolente: contra o desperdício da experiência. $4^{\mathrm{a}}$ ed. São Paulo: Cortez, 2002.

Pela mão de Alice: o social e o político na pós-modernidade. São Paulo: Cortez, 1995.

SOUZA, E.C. (org.) Autobiografias, histórias de vida e formação: pesquisa e ensino. Porto Alegre: EDIPUCRS, 2006.

\section{Notas}

\footnotetext{
${ }^{1}$ Maria é um nome fictício, pois optamos por preservar a identidade dos depoentes.

${ }^{2}$ Nome fictício.

${ }^{3}$ Professora 1.
} 